\title{
Ecosistemas multiactor en la Cooperación Sur-Sur: un prerrequisito para lograr la apropiación nacional ${ }^{*}$
}

Analilia Huitrón Morales**

\section{RESUMEN}

El objetivo de este artículo es estudiar el grado en el que se vinculan los actores no estatales a la gobernanza y práctica de la cooperación Sur-Sur como un prerrequisito en el cumplimiento de la apropiación nacional. Para ello se realiza un análisis empírico de las experiencias de México, Chile y Colombia, y su oferta de css técnica. En primer lugar, se analizan los marcos normativos y de gestión sobre los que descansan la css de los tres países, identificando en qué medida estimulan la integración de diversos actores y cómo se materializa; y, en segundo lugar, se contrasta el grado de participación de actores estatales y no estales en las iniciativas de cooperación a partir del análisis de 41 proyectos de css técnica de los tres países.

Palabras clave: Cooperación Sur-Sur, ecosistema multiactor, México, Chile, Colombia.

* Esta publicación se deriva de la Tesis Doctoral defendida por la autora en la Facultad de Ciencias Económicas y Empresariales de la Universidad Complutense de Madrid, en diciembre de 2018.

** Doctora en economía con especialidad en economía internacional y desarrollo. Consultora independiente e investigadora asociada Universidad Complutense de Madrid (España). [ahuitron@ucm.es], [https://orcid.org/00000001-8344-4894].

Recibido: 11 de junio de 2019 / Modificado: 26 de julio de 2019 / Aceptado: 1 de agosto de 2019

Para citar este artículo:

Huitrón, A. (2020). Ecosistemas multiactor en la Cooperación Sur-Sur: un prerrequisito para lograr la apropiación nacional. OASIS, 31, pp. 73-99

DOI: https://doi.org/10.18601/16577558.n31.06 


\section{Multi-stakeholder ecosystems in South-South cooperation: a prerequisite for achieving na- tional ownership}

\section{ABSTRACT}

The objective of this article is to study the degree to which non-governmental actors are linked to the governance and practice of South-South Cooperation as a prerequisite to the achievement of the principle of ownership. To accomplish this objective, three cases are analyzed empirically: Mexico, Chile and Colombia, and their technical ssc. Firstly, the normative frameworks of the three countries are analyzed to identify to what extent they stimulate the integration of diverse actors and how that materializes; and, secondly, a contrast will be made of the degree of participation of governmental and non-governmental actors in SSC initiatives through the analysis of 41 projects of Mexico, Chile and Colombia.

Key words: South-South Cooperation, Multiactor Ecosystems, Mexico, Chile, Colombia.

\section{INTRODUCCIÓN}

A lo largo de las últimas décadas, el Sistema Internacional de Cooperación para el Desarrollo (SICD) ha experimentado cambios en su estructura, procesos y actores. Uno de los más relevantes es la mayor apertura hacia nuevos actores, que no solo alude a países en desarrollo como proveedores de cooperación, sino también a actores no estatales por su rol activo como agentes de cambio.

Si bien los actores no estatales - sociedad civil, empresas, fundaciones, academia- siempre han sido parte activa de la dinámica de la cooperación para el desarrollo, su experiencia acumulada los ha posicionado en los últimos años como fuentes de conocimientos, recursos, capacidades y tecnología, generando -y requiriendo- nuevas formas de vincularse con los actores públicos en favor de una cooperación coordinada y eficaz en su propósito. Esta irrupción de los actores no estatales en el SIDC, a la vez que supone una oportunidad para generar alianzas en favor de la implementación de la cooperación para el desarrollo, también supone un desafío, dado que la narrativa y configuración del sIDC se ha establecido en torno a un actor principal: el Estado nacional. El diseño, gestión, implementación y evaluación de la cooperación al desarrollo se ha centrado en las normativas y políticas públicas que desarrollan los Estados nacionales (Calvento y Rolandi, 2015), siendo los actores por excelencia de la cooperación internacional al desarrollo.

Esta dinámica monoactor, no es ajena en la cooperación Sur-Sur (css), una modalidad que pretende ser novedosa (pese a su larga data) frente a la cooperación Norte-Sur y promover lógicas más participativas, pero cuyo propósito descansa en el fortalecimiento de las instituciones gubernamentales de los países que la practican, concentrando, de nuevo, el protagonismo en los Estados. Daniel Bobiash (1992) tras elaborar uno de los estudios pionero sobre evaluación de la css, ya revelaba que la participación de actores no estatales en los proyectos 
e iniciativas de esta modalidad de cooperación era prácticamente inexistente. Pero no ha sido hasta principios de la segunda década del siglo XXI que se han alzado voces críticas de actores no estatales, sobre todo desde la sociedad civil, buscando influir en la css (Dolcetti, 2014; Balbis, 2013; entre otros).

Tales críticas se hacen eco de planteamientos teóricos respecto a la importancia de la participación de los agentes no estatales en el diseño y práctica de la cooperación para generar una verdadera "apropiación democrática” (Dubois 2001, p. 105), así como de las declaraciones gubernamentales en torno a la css en las que se reconoce que

la css comprende la participación de múltiples partes interesadas, incluidas las organizaciones no gubernamentales, el sector privado, la sociedad civil, las instituciones académicas y otros agentes que contribuyen a hacer frente a los problemas y alcanzar los objetivos en materia de desarrollo de conformidad con las estrategias y los planes nacionales de desarrollo (NU, 2009, párr. 19).

Lo anterior pone en evidencia la relevancia de crear ecosistemas multiactores en la css con el fin de contribuir en la construcción de un SICD como un proyecto social en el que existan formas creativas y diversas de entendimiento y diálogo entre los actores no estatales y el Estado, poniendo en práctica experiencias de css que estimulen una verdadera "apropiación democrática”. Así, la generación de estrategias y mecanismos que permitan la incorporación de actores no estatales como protagonistas de la css se convierte en uno de los desafíos de esta modalidad importantes por superar (Segib,
2018). Por ello, el objetivo de este documento es estudiar el grado en el que se vinculan los actores no estatales a la práctica de la css, habilitando una gobernanza que promueva el diálogo continuado y estratégico entre los actores gubernamentales y no gubernamentales, siendo una prerrogativa en el cumplimiento de la apropiación nacional.

Para el cumplimiento de este objetivo, el artículo se estructura en cinco apartados. El primero, después de esta introducción, expone la relevancia, la participación de diversos actores en la práctica de la css, poniendo énfasis en la generación de ecosistemas multiactor. El segundo apartado se enfoca en explicar la metodología a través de la que se pretende cumplir con el objetivo de este documento. El tercero y cuarto se centran en el análisis empírico, revisando los casos de estudio: México, Chile y Colombia, y contrastando el principio de apropiación nacional en la práctica, respectivamente. En las conclusiones será posible reflexionar acerca de cómo avanzar en la consolidación de ecosistemas multiactor en la css y promover una cooperación inclusiva y participativa.

\section{CONTEXTO: PARTICIPACIÓN MULTIACTOR EN LA CSS COMO ELEMENTO CLAVE DE LA APROPIACIÓN NACIONAL}

La Agenda de Desarrollo Sostenible 2030 (Agenda 2030) y sus 17 Objetivos de Desarrollo Sostenible (oDs) y 169 metas, obliga a poner el foco en la necesidad de impulsar el desarrollo desde una lógica multidimensional, multinivel y multiactor. Multidimensional, poniendo el énfasis en las interconexiones e 
interdependencias existentes entre los diversos objetivos y metas, de tal forma que para avanzar en buena parte de ellos será necesario alcanzar logros simultáneos en muchos otros, obligando, por tanto, a adoptar fórmulas de trabajo más transversales que las que generalmente han prevalecido hasta la fecha (Le Blanc, 2015); multinivel, en tanto que la consecución de los oDs si bien atribuye un papel fundamental a los Estados, también precisa la existencia de estructuras de gobernanza supraestatales (regionales y globales) y de la implicación y participación de los gobiernos subestatales y locales, que deberán adoptar y adaptar los oDs a sus realidades y condiciones específicas; y multiactor, pues el logro de los propósitos que persigue la Agenda 2030 no podrán alcanzarse con la participación exclusiva de los poderes públicos, sino que será necesario integrar los esfuerzos de actores diversos no estatales y capitalizar las contribuciones, que cada uno de ellos puede realizar, a partir de su naturaleza y potencialidades específicas (Huitrón y Santander, 2018).

La Agenda 2030, a partir de su perspectiva más integral y comprehensiva obliga, también, a ampliar el repertorio de mecanismos de apoyo y fuentes de financiación con los cuales respaldar el logro de los oDs en sintonía con el principio de "responsabilidades comunes, pero diferenciadas". Por ello, resulta relevante la contribución que hagan los países en desa- rrollo, no solo por su capacidad para movilizar los recursos domésticos al servicio del cumplimiento de los compromisos adquiridos en la Agenda a nivel nacional, sino también por la contribución que puedan hacer, a través de fórmulas de cooperación como la css, triangu$\operatorname{lar}^{1}$ y la cooperación regional, a los procesos de desarrollo de países con retos similares. En este sentido, la Agenda 2030 deja claro la relevancia de la css siendo acogida dentro de los oDs al referirla en el objetivo 17 , relativo al fortalecimiento de los medios de implementación y revitalización de la Alianza Mundial para el Desarrollo Sostenible. De manera particular, las metas 17.6 y 17.9 convocan a mejorar la cooperación regional e internacional NorteSur, Sur-Sur y triangular en materia de ciencia, tecnología e innovación y el acceso a estas, y a aumentar el apoyo internacional para realizar actividades de creación de capacidades eficaces y específicas en los países en desarrollo a fin de respaldar los planes nacionales de implementación de todos los oDs, incluso mediante la cooperación Sur-Sur y triangular, respectivamente.

No obstante, a los cambios descritos que introduce la Agenda 2030, la css se ha caracterizado -nuevamente- por un protagonismo de los Estados como actores principales del diseño e implementación de las iniciativas que se dan en el seno de esta modalidad de cooperación. La Css ha sido, prioritariamente, una cooperación gubernamental, cuya estrategia de

\footnotetext{
La cooperación triangular trata de un esquema mixto en el que intervienen tres actores: un país u organismo internacional que provee los recursos financieros, otro país que provee los medios técnicos y humanos, y un país beneficiario (diferente a los dos anteriores) que, además, puede añadir sus propios recursos (Glosario "La realidad de la ayuda”, Oxfam México).
} 
trabajo se encuentra centrada en las acciones y capacidades de los Estados, con participaciones limitadas de otros actores no estatales (Apci, 2016). En este sentido, la Secretaría General Iberoamericana (Segib) destaca "la importancia de promover la participación social y la articulación con otros actores en los planes y actividades de cooperación (...). Contar con Consejos de Cooperación con competencias significativas y marcos estables, sería un paso positivo" (Segib, 2010, p. 149). También, en esta línea, la Alianza Global para una Cooperación Eficaz al Desarrollo (Agced) creada en el Cuarto Foro de Alto Nivel (FAN) sobre la Eficacia de la Ayuda en Busan (2011), resaltó la importancia de los actores no estatales en la arquitectura global de la cooperación del desarrollo, con especial énfasis en la css y Triangular, y señaló la utilidad de crear "alianzas incluyentes para el desarrollo”, basadas en la apertura, la confianza, el respeto, el aprendizaje mutuo y el reconocimiento de la diversidad y complementariedad de las funciones que cada actor puede desempeñar, en una clara alusión a lógicas público-privadas (Balbis, 2013).

$\mathrm{Al}$ respecto, algunos autores han teorizado sobre la participación de los actores que influyen en la evolución de la cooperación internacional más allá del Estado, siendo agentes de la "apropiación democrática" (Dubois, 2001; Pino y Linaje, 2012). Esto alude a que los espacios y contenidos de la participación de los distintos actores de la cooperación "tienen que garantizar el avance desde criterios meramente consultivos o referenciales hacia una participación efectiva, facultativa y discrecional que aborde todos los elementos del proceso" (Pino y Linaje, 2012, p. 26). En este sentido, la participación de los actores no estatales ha de darse en todas las etapas de la cooperación para el desarrollo: desde su formulación y discusión; hasta el seguimiento, evaluación y rendición de cuentas, pasando por su implementación mediante acciones y proyectos (Dolcetti, 2014).

En la doctrina de la css la apropiación nacional, al igual que los principios fundamentales de horizontalidad, respeto a la soberanía nacional, la no condicionalidad, la no injerencia en los asuntos internos y el beneficio mutuo, debe guiar la gestión y práctica de las acciones de colaboración Sur-Sur (Naciones Unidas, 2009; DESA/RIs, 2013). La apropiación nacional ${ }^{2}$ en la css ha de entenderse como un proceso endógeno de formulación de políticas y fortalecimiento de capacidades técnicas e institucionales bajo el liderazgo de los países demandantes y de acuerdo con sus criterios y necesidades que emergen de un ejercicio de participación colectiva, motivando la participación multiactor (Saiia, 2017). La Declaración de Nairobi (2009), por su parte, también reconoce que

la cooperación Sur-Sur comprende la participación de múltiples partes interesadas, incluidas las organizaciones no gubernamentales, el sector privado, la sociedad civil, las instituciones académicas y otros agentes que contribuyen a hacer frente a los problemas

2 También se puede encontrar en otras referencias como "implicación nacional”. 
y alcanzar los objetivos en materia de desarrollo de conformidad con las estrategias y los planes nacionales de desarrollo” (Naciones Unidas, 2009, párr. 19).

Por tanto, un enfoque de múltiples actores en la css ha de estar presente en los procesos de identificación, formulación, implementación y evaluación de las iniciativas y programas de este tipo de modalidad, a fin de que esto pueda contribuir a la sostenibilidad de los propósitos de la css (Brics y Articulação Sul, 2017).

Teniendo en cuenta lo anterior, el debate ha de superar la cuestión en torno a si los actores no estatales deben tener un rol protagónico en la css más allá de ser el "brazo ejecutor" 3 de la cooperación y, por el contrario, evolucionar hacia cómo ha de generarse un "ecosistema multiactor"(Krupatini, 2011) en el que se logre mayor grado de integración y articulación del conjunto de actores sociales en los procesos institucionales de esta modalidad de cooperación, creando directrices, políticas y estructuras que contemplen los espacios de encuentro e intercambio entre los agentes gubernamentales y no estatales, teniendo posibilidades reales de injerencia en todas las etapas de la gestión de la cooperación, incluida la promoción de la transparencia y los ejercicios de rendición de cuentas. Un ecosistema multiactor no solo permitiría la coherencia doctrinal de la css en particular con el principio de apropiación nacional-, sino, sobre todo, se espera consti- tuya un sistema en torno a la css eficiente y sostenible que estimule avanzar en esquemas acordes con la participación inclusiva y la generación de alianzas que propone la Agenda 2030 para no dejar a nadie atrás en el camino del desarrollo (Apci, 2016).

\section{METODOLOGÍA}

Por lo anteriormente revisado, en este documento se hace uso de una metodología de evaluación cualitativa sobre el funcionamiento y los resultados de la css, desarrollada en una investigación más amplia (Huitrón, 2018). Esta metodología contempla dos niveles de evaluación: i) nivel macro: normativo-institucional; y ii) nivel micro: proyectos de cooperación.

- Nivel macro. El nivel macro tiene que ver con un componente normativo-institucional de la css, el cual está orientado a analizar los marcos jurídicos, normativos y mecanismos operativos sobre los que descansa la práctica de esta cooperación, reconociendo hasta qué punto los elementos que, según los propios países del Sur, deben guiar la política de css se encuentran en estos marcos institucionales de los países que practican esta modalidad de cooperación.

- Nivel micro. En cuanto al nivel micro este se focaliza en los proyectos concretos de

3 En la cooperación tradicional (Norte-Sur) el papel de actores no estatales, particularmente la sociedad civil, ha sido reconocido desde una perspectiva más instrumental que protagónico. La participación de estos actores ha de entenderse más desde la ejecución de los proyectos de desarrollo que desde el diseño y/o la evaluación de las iniciativas de cooperación. 
Css. Esta evaluación se concentra en los procesos de implementación y resultados de los proyectos.

\section{Instrumentos para la recolección de información y datos}

- Nivel macro. Para recolectar, organizar e interpretar la información del primer componente, la metodología propone una matriz de evaluación cualitativa diseñada a partir de cuatro elementos propios de la css: apropiación nacional pertinencia reciprocidad y horizontalidad ${ }^{4}$. Estos elementos se operativizan en un total de 30 indicadores cualitativos. Para este estudio solo se utilizará lo relativo a la apropiación nacional y a la participación multiactor, pues son los que se relacionan directamente con el objetivo de la investigación, vinculando tres indicadores cualitativos:
1. Participación de grupos sectoriales en la identificación, definición e implementación de la demanda;

2. Existencia de mecanismos de coordinación y articulación con diversos actores-gubernamentales y no gubernamentales;

3. Existencia de la vinculación de actores no gubernamentales en la identificación e implementación de las iniciativas de css.

- Nivel micro. Para recolectar los datos que permiten el análisis a nivel proyecto, la metodología propone un cuestionario alineado a los elementos propios de la css que recoge la matriz, con el fin de mantener una coherencia conceptual y procedimental entre el nivel macro y micro. El cuestionario contempla 26 preguntas. Para este estudio solo se contemplan las

4 Se describe brevemente los elementos de pertinencia, reciprocidad y horizontalidad. Pertinencia. La pertinencia en la css tiene que ver con la adecuación de las iniciativas de cooperación a los objetivos de desarrollo fundamentales de los países receptores, así como a los contextos y capacidades nacionales de los países socios a fin de que la aplicación de las acciones cumpla con los objetivos propuestos (Paba, 1978). En este sentido, la pertinencia se asocia a la alineación de la demanda con el plan nacional o con los planes sectoriales de desarrollo del país que la solicita y la capacidad técnica de los países socios. Reciprocidad. Este elemento remite a una distribución aceptable de las responsabilidades técnicas, así como de los beneficios que se deriven de las intervenciones por parte de ambas partes de la relación. Asimismo, debe aplicarse a la distribución de costos, en el sentido de que las responsabilidades financieras deben asumirse de manera compartida, pero proporcional a las posibilidades reales de cada contraparte. De esta manera, se intenta romper con dinámicas jerarquizadas, impulsando, por el contrario, relaciones de mayor corresponsabilidad entre los socios. Horizontalidad. Implica que la relación de colaboración se establezca de manera voluntaria (intención de cooperar), consensuada, bajo un esquema de solidaridad y confianza, y sin que ninguna de las partes ligue su participación al establecimiento de condiciones y/o imposiciones políticas (Segib; 2010). De esta manera, se busca que las relaciones de colaboración entre los países en desarrollo rompan con lógicas jerarquizadas vinculadas a las asimetrías que pueden existir entre los socios en cuanto a sus niveles de renta y/o de poder y, por el contrario, se estimula una relación de cooperación en condiciones de igualdad. 
preguntas vinculadas a la apropiación nacional:

1. ¿El proyecto de css en el que participó/a fue solicitado por el socio beneficiario, el socio oferente (país que transfiere el conocimiento y/o la experiencia) o por ambas partes?

2. ¿A través de qué instrumento, mecanismo o canal se realizó la solicitud del proyecto de css en el que participó/a?

3. De acuerdo con su experiencia general en la ejecución de proyectos de cooperación Sur-Sur, ¿̇en qué grado consideran que participan cada uno de estos actores en la identificación, diseño, negociación y aprobación del proyecto?

4. Valore el grado en que el socio receptor tuvo capacidad de decisión efectiva en cada una de las etapas del proyecto de css en el que participó/a.

5. Con base en su experiencia en la ejecución de proyectos de cooperación, por favor indique el grado de participación que considera que tiene el socio receptor en la toma de decisiones en cada una de estas modalidades de cooperación: css bilateral/horizontal; css bilateral/nivel de renta inferior/ superior; CTriangular; cooperación Norte-Sur

\section{Fuentes de información}

- Nivel macro. Para recolectar la información del nivel macro se recurre a fuentes secundarias y primarias, que consiste en una revisión de la literatura y documentos oficiales a fin de indagar en los principales marcos normativos y mandatos en los que se sustentan la política de css de los tres casos de estudio. Asimismo, se realizaron una serie de entrevistas semiestructuradas a los principales actores gubernamentales y no gubernamentales vinculados a la css de los tres países.

- Nivel micro. Para la recolección de datos a nivel micro se recurre a los principales responsables de la ejecución de los proyectos de css de los tres casos de estudio a los que se les aplicó el cuestionario.

\section{Muestra de proyectos para la aplicación del cuestionario}

Para realizar el análisis micro se cuenta con una muestra de 55 proyectos de cooperación técnica ofertados por los países estudiados: México, Chile y Colombia, ejecutados entre 2008 y 2017. La base de datos incluye información homogénea para los tres países: fecha de inicio y finalización, país socio (beneficiario), institución ejecutora nacional, institución ejecutora en el país socio, sector, modalidad de cooperación (horizontal bilateral, triangular o regional), convenio jurídico, que tuvieran una duración de más de 3 meses y con más de dos actividades, y que fueran acordados entre gobiernos y aprobados en un marco de cooperación compartido entre las partes (comisión mixta, acuerdo interinstitucional, acuerdos generales de cooperación o 
similares) $)^{5}$. Asimismo, se cuenta con el contacto de 118 personas responsables de la gestión e implementación de los 55 proyectos, tanto de los países proveedores como de las contrapartes beneficiarias.

\section{Datos para el análisis micro}

En cuanto a los datos que se utilizan para el análisis en torno al grado en el que se observa la participación de los actores sociales en los proyectos de css, se recogen los datos obtenidos de la aplicación del cuestionario entre los meses de julio y septiembre de 2017 a las personas ejecutoras y beneficiarias de la muestra de los proyectos de css. El cuestionario recoge la valoración de 70 personas que respondieron en tiempo y forma al total de las preguntas planteadas, teniendo una tasa final de respuesta del $60 \%$ del total de las 118 personas contactadas, correspondientes a 41 de los 55 proyectos (es decir, el 75\%) considerados.

Una vez que se tienen los datos, es prescindible codificar las respuestas para medir el grado en el que la apropiación nacional y, por tanto, la participación multiactor se observan en los proyectos de css. Para ello, se han determinado tres variables: demanda (“d”), capaci- dad de decisión del socio beneficiario ("cde”) y participación multiactor (“p_ma”). El valor para cada una de las variables se corresponde de la siguiente manera:

- Variable "d", se codificó en una escala de 0 a 2, donde 0 es si la solicitud fue hecha por el socio oferente, 1 si fue realizada por ambos en países de un acuerdo previo, o 2 si la solitud fue realizada por el socio demandante bajo un marco jurídico acordado por las partes.

- Variable "p_ma”, adquiere el valor de $0 \mathrm{a}$ 3 , donde 3 se considera una participación efectiva por parte del actor, 2 si participan solo en la identificación y diseño del proyecto, 1 si participan solo en consultas y con insumos o 0 si no participan en ninguna etapa del proyecto.

- Variable "cde", se codificó en una escala de 0 a 3 , donde 3 corresponde a una alta capacidad en la toma de decisiones, 2 bastante, 1 poco y 0 nada.

Dado que las variables adquieren una escala de medición diferente, es necesario estandarizar el valor a fin de que se puedan comparar. Para

\footnotetext{
5 Esta identificación de elementos busca excluir acciones puntuales o proyectos que hayan sido establecidos de manera directa desde el más alto nivel gubernamental o unilateralmente. Así, el reconocimiento de proyectos sustanciales se recoge, entre otras referencias, de la definición que la Segib sugiere sobre un proyecto de cooperación: "Conjunto de acciones encaminadas a satisfacer un objetivo común hacia un destinatario específico, a través de su ejecución en el marco de uno o varios sectores y/o temas. Posee los siguientes elementos: período de ejecución definido, presupuesto, resultados esperados, programa en que se inserta; e igualmente, debe prever un mecanismo de seguimiento y evaluación. Se habrá aprobado en un marco de cooperación (comisión mixta, acuerdo interinstitucional, acuerdos generales de cooperación, o similares)" (Segib, 2010, p. 25).
} 
ello, se "normalizan" en una escala del 0 al 1, de acuerdo con la siguiente formula:

$$
\mathrm{V}=\{V e-V \min \} /\{V \operatorname{máx}-V \min \}
$$

Donde "V" es la variable cuyo valor se desea estandarizar, "e" expresa el valor máximo efectivo alcanzado para ese proyecto, el subíndice "min" se refiere al valor mínimo de la variable y el subíndice "máx" se refiere al valor máximo de la variable en cuestión. Una vez realizada esta estandarización para cada una de las variables, el valor posible de cada variable se encuentra entre el 0 y el 1.

Siguiendo esta metodología, se espera, por un lado, validar los indicadores cualitativos que aluden a la apropiación nacional en los marcos normativos e institucionales de los tres casos de estudio y, por otro, recoger la percepción y valoración que los responsables de diversos proyectos de css tienen en torno a la consistencia normativa de esta modalidad, contrastando la aplicación del principio de apropiación nacional y la vinculación de distintos actores sociales en la práctica.

\section{Selección de los casos de estudio}

La elección de los tres estudios de caso no es caprichosa: México, Chile y Colombia son países del mundo en desarrollo y, particularmente, de América Latina, y se han posicionado en el último lustro como países que son actores relevantes en la cooperación para el desarrollo. Además de su rol dual como receptor y proveedor son países que han avanzado constantemente en los procesos de institucionalización, gestión y medición de la css en la región. Esto hace que el grupo de países que se analiza tenga características similares en torno a la institucionalización y práctica de la css, permitiendo centrar el análisis en el grado de inclusión de actores no gubernamentales en la css de los países en desarrollo que muestran un avance relevante en la materia.

\section{ECOSISTEMAS MULTIACTOR EN LA CSS: EXPERIENCIAS DE MÉXICO, CHILE Y COLOMBIA}

En este apartado se revisará la normativa vigente que permite la planificación y ejecución de la css en México, Chile y Colombia, analizando la existencia y funcionamiento de los mecanismos que permiten la vinculación de actores no estatales en la cooperación que ejecutan estos tres países y sus desafíos para consolidar un ecosistema multiactor efectivo.

\section{a. México}

México ha logrado conformarse como una referencia entre los países del Sur en materia de cooperación internacional. Varios son los factores que sustentan tal percepción: su progresivo papel como oferente de cooperación en países de América Latina y Asia Pacífico; su papel como receptor de ayuda, consolidando una relación de colaboración con los donantes tradicionales, lo que le ha permitido ser un actor promotor de la cooperación triangular, creando alianzas estratégicas con organismos multilaterales y algunos países desarrollados; su participación como facilitador de diálogo en foros internacionales con capacidad para ser puente entre países en desarrollo y países 
desarrollados, dada su pertenencia a la Ocde; y la consolidación de un marco institucional y normativo de la cooperación internacional mexicana, a partir de un mandato de ley que entró en vigor en 2011. En función de todo ello, se le reconoce a México el estatus de actor "polivalente" (Tripp y Vega, 2011).

\section{Normativa}

En abril de 2011 es aprobada la Ley Mexicana de Cooperación Internacional para el Desarrollo (LCID), representando un hito en la institucionalización de la cooperación mexicana y proveyendo los instrumentos normativos para una política en la materia. La LCID establece los objetivos ${ }^{6}$, principios $^{7}$ y lineamientos que buscan asegurar la complementariedad de la cooperación mexicana con los esfuerzos propios de los países, la autosostenibilidad de los procesos de desarrollo y la apropiación por parte de los receptores de la oferta de cooperación mexicana, por medio del cofinanciamiento y otros aportes de las diferentes partes involucradas. Su propósito es dotar de mayor institucionalidad a la cooperación mexicana "a través de la conformación de instancias y mecanismos de gestión y financiamiento que resistan los embates propios a los cambios del gobierno federal" (Prado, 2013, p. 182).

$\mathrm{El}$ andamiaje institucional de la cooperación mexicana que emana de la LCID está constituido por cinco pilares: la Amexcid (institución coordinadora); el Programa de Cooperación Internacional para el Desarrollo (Procid, instrumento programático para la planeación y ejecución de las acciones de cooperación internacional); el Fondo Nacional de Cooperación Internacional para el Desarrollo (Foncid, pilar financiero cuya instrumentación se encuentra en proceso de desarrollo y se espera entre en funcionamiento para el ciclo 2015-2016); y el Registro Nacional y Sistema de Información de Cooperación Internacional para el Desarrollo (Rencid y Sicid, seguimiento, registro y cuantificación de la cooperación).

En abril de 2014 fue publicado el Decreto por el que se aprobó el Programa de Cooperación Internacional para el Desarrollo (PROCID) 2014-2018 ${ }^{8}$, en el que se establecieron las estrategias y principios rectores de la cooperación mexicana para este período, trazando al mismo tiempo las prioridades temáticas y geográficas. El Procid, si bien se encuentra en una fase de revisión para su renovación y aplicación en el período 2020-2024,

\footnotetext{
6 La erradicación de la pobreza, el desempleo, la desigualdad y la exclusión social; el aumento permanente de los niveles educativo, técnico, científico y cultural; la disminución de las asimetrías entre los países desarrollados y países en vías de desarrollo; la búsqueda de la protección del medio ambiente y la lucha contra el cambio climático; así como el fortalecimiento a la seguridad pública.

7 La solidaridad internacional, la defensa y promoción de los derechos humanos, el fortalecimiento del Estado de derecho, la equidad de género, la promoción del desarrollo sustentable, la transparencia y rendición de cuentas y los criterios de apropiación, alineación, armonización, gestión orientada a resultados y mutua responsabilidad.

8 Véase documento en https://www.gob.mx/cms/uploads/attachment/file/109684/ProciD.pdf
} 
es el documento en el que se señala lo imprescindible que resulta "diseñar mecanismos de interacción y fortalecer los existentes, así como identificar las instancias que permitan construir una política abierta e incluyente" (Procid, sección 1.4, p.10).

\section{Ecosistema multiactor y su funcionamiento}

La LCID en sus artículos 4, fracción viII, 16, y 19, fracción vI, se prevé el establecimiento de consejos técnicos, "con objeto de sistematizar el diálogo de la propia Agencia con otros cooperantes mexicanos en temas especializados" (Procid, sección 1.4, p. 11). Al respecto, en noviembre de 2012, se aprobó la creación de cinco consejos técnicos y en 2015, en el marco de la vir Sesión Ordinaria del Consejo Consultivo de la Amexcid, se aprobó un sexto:

1. Consejo Técnico Académico y Científico

2. Consejo Técnico Empresarial

3. Consejo Técnico de Gobiernos Locales

4. Consejo Técnico Social

5. Consejo Técnico Asesor de Alto Nivel

6. Consejo Técnico del Agua.

La creación de estos consejos técnicos ad hoc de "carácter consultivo" tiene como propósito sistematizar el diálogo entre la Amexcid con el resto de los actores tanto locales como no gubernamentales. Y es la Amexcid la instancia que "coordinará la celebración de las sesiones del Consejo Consultivo", de los consejos técnicos ad-hoc y demás reuniones de coordinación con otros actores" (Procid, sección 1.4, p. 10).

En cuanto a su funcionamiento, los consejos técnicos ad hoc deben reunirse de manera regular-sin un período de tiempo estipuladoy diseñar planes de trabajo para la ejecución de proyectos conjuntos. No obstante, respecto a las actividades que en su seno se han podido determinar, no se tiene conocimiento de ningún documento público que permita constatar las reuniones regulares que debieran llevarse a cabo ni, por tanto, los planes de trabajo previsto.

\section{Desafíos}

Si bien la creación de estos mecanismos de diálogo constituye una iniciativa innovadora, ya que raramente se presentan en los procesos de institucionalización de la cooperación de los países del Sur, hay evidencia de que son estructuras que no han logrado funcionar de manera eficaz por el momento. La Amexcid no ha tenido capacidad institucional para convocar de manera sistemática a los consejos técnicos. Quizá uno de los más activos es el del sector privado que ha constituido la Alianza

9 Esta instancia es el principal mecanismo de coordinación y comunicación entre la Amexcid y el resto de las instituciones gubernamentales. El Consejo Consultivo, de acuerdo con la LCID, está integrado por un representante de cada una de las secretarías (Ministerios) y entidades de la APF, quienes tendrán derecho a voz y voto. En enero de 2012 el Consejo Consultivo de la Amexcid se constituyó con la participación final de 17 secretarías de Estado y tres entidades de la Apf: Consejo Nacional de Ciencia y Tecnología (Conacyt), Consejo Nacional para la Cultura y las Artes (Conaculta) y la Comisión Nacional para el Desarrollo de los Pueblos Indígenas (CDI). 
por la Sostenibilidad ${ }^{10}$, pero el dinamismo no es igual en todos, algunos de ellos han sesionado de manera irregular.

Hay un cuestionamiento importante respecto a la composición de los propios comités, pues en el caso del académico, se convoca a altos mandos de instituciones académicas que no necesariamente se encuentran familiarizados con la cooperación internacional. El Consejo Técnico Social (vinculado con la participación de la sociedad civil) ha buscado que se convoque a todos los consejos de manera simultánea, en una lógica multiactor, pero no ha sido posible. Por su parte, el Consejo Técnico de los Gobiernos Locales se "reinstalaba" en 2018. La Amexcid tiene claro que es importante la inclusión de los demás actores, a pesar de que no son considerados sujetos de la Ley, pero parece no tener capacidad institucional para darle seguimiento a la iniciativa. Al primer año de la administración del presidente Andrés Manuel López Obrador aún es pronto para saber si han sufrido cambios estos mecanismos, por lo que habrá que estar al tanto de cómo evolucionan y si se continúa en su fortalecimiento.

$\mathrm{Al}$ respecto, desde la academia, se reclama la necesidad de adoptar estrategias diversas de comunicación, colaboración, compromiso, rendición de cuentas y trabajo conjunto a fin de que estos mecanismos de coordinación cumplan no solo con el objetivo de retroalimentar de manera efectiva a la Amexcid, sino también de hacer mucho más eficiente la cooperación mexicana. De manera complemen- taria, se sugiere fomentar un diálogo abierto más allá de estos mecanismos de coordinación institucionales para que existan canales de comunicación más flexibles y comprehensivos (páginas webs, grupos de debate virtuales, por ejemplo) que promuevan el intercambio de ideas y propuestas (Bracho G. y Pérez J. A., 2015).

Así, el desafío principal en torno a la creación y funcionamiento de ecosistemas multiactor en México, tiene que ver con la necesidad de consolidar un compromiso por parte de Amexcid para establecer, de forma creativa, mecanismos de diálogo con la sociedad civil, sector privado y academia. Se trata de establecer una relación que motive una retroalimentación valiosa y de provecho que permita el trabajo multiactor que requiere la puesta en marcha de la cooperación internacional.

\section{b. Chile}

Con el retorno a la democracia, Chile ha dedicado esfuerzos a consolidar sus instituciones y mejorar sus políticas públicas. En este proceso, Chile ha pasado de ser un país receptor neto de cooperación, en 1990, a cumplir un rol dual recibiendo y prestando cooperación para el desarrollo. El país comenzó un proceso de reincorporación a la comunidad internacional "coincidiendo con el nuevo proceso de globalización, en la era de la post-guerra fría" (Walker, 2006, p. 18). El gobierno democrático de Patricio Aylwin (1990-1994) trató de

10 Véase enlace https:/www.gob.mx/amexcid/acciones-y-programas/alianza-por-la-sostenibilidad 
reposicionar al país, utilizando la cooperación internacional como uno de los ejes centrales de su política exterior y retomando el diálogo y los acuerdos tanto a nivel bilateral como multilateral (Barros van Buren, 1990, pp. 108-109).

Si bien, durante los primeros años de la transición democrática los donantes tradicionales dedicaron importantes recursos de AOD al fortalecimiento institucional y a la creación de una estructura política que permitiera consolidar la democracia en Chile ${ }^{11}$, a finales de la década de los noventa el país dejó de recibir cooperación financiera no reembolsable dado el aumento que registraba en sus niveles de desarrollo relativo. El descenso de la ayuda y la consolidación de un proceso de desarrollo contribuyó a que Chile transitara de un país receptor a un país proveedor de css basada en costos compartidos (Herrera, 2009; Santander, 2016).

En tal contexto, Chile redirige su política de cooperación para impulsar la css como una estrategia complementaria a su política exterior de reinserción internacional (Lazo citada en López, 2014, p. 50). Actualmente, Chile destaca como un país pivote tanto de la css como de la cooperación triangular, posicionándolo dentro de los cinco países con mayor oferta de cooperación técnica en la región de Iberoamérica, de acuerdo con los informes anuales de la Segib (2007-2018).

\section{Normativa}

A medida que Chile fue avanzando en su desarrollo y proceso de democratización, la estrategia y normativa de la cooperación internacional también sufrió modificaciones. Si bien la cooperación chilena no se sustenta en una Ley de cooperación, existen una serie de reglamentos y decretos que han ido dotando de elementos normativos a la política de cooperación $^{12}$.

En 2015, coincidiendo con la aprobación de la Agenda 2030, el gobierno chileno redefinió su política de cooperación internacional, pasando de "un enfoque reactivo o de corto plazo, a políticas de largo plazo, con horizontes estratégicos, de manera que contribuya al logro de los objetivos de desarrollo" (AGCID, 2015) se definieron la Política Chilena de Cooperación Internacional para el Desarrollo 2030 y la Estrategia de Cooperación Internacional para el Desarrollo 2015-2018. De acuerdo con el documento publicado en 2015, las principales directrices de la Política de Cooperación de Chile a 2030 son:

- Reafirmar que el eje de su cooperación sigue estando en la región de Latinoamérica, fortaleciendo los distintos mecanismos de integración existentes, el rol de la región en la gobernanza mundial y

11 En 1996 registró su máximo histórico de recepción de AOD, con más de 195 millones de dólares.

12 Véase: Ley $N^{\circ} 19.989$ de 1990; Instructivo $N^{\circ} 001$ de 1995; Ley Nº 19.999 de 2005 modifica la Ley $\mathrm{N}^{\circ} 18.989$; Resolución Nº9 de marzo de 2015; Resolución No 241 de 2015; y Decreto $N^{\circ} 1613$. 
la convergencia en América Latina y el Caribe.

- Modificar la actual sigla "AGCI" por "AGCID”, optando explícitamente por una política de cooperación que asume un enfoque multidimensional y de derechos que fortalezca la cohesión social y la sostenibilidad ${ }^{13}$.

- Impulsar la css, transitando de acciones puntuales de formación y asistencia técnica hacia un programa integrado en la política exterior.

- Contribuir al fortalecimiento de la democracia en la región, la transparencia y la rendición de cuentas, así como la participación de la sociedad civil, sector privado y los grupos más vulnerables en los procesos democráticos y de desarrollo.

A la vez, la Estrategia de Cooperación Internacional de Chile para el Desarrollo diseña la política para el período 2015-2018, coincidente con el período del gobierno de Michelle Bachelet. Esta Estrategia se implementa bajo cinco "criterios orientadores" que son los principios que guiaran los "objetivos estratégicos" y, a su vez, las "áreas transversales" que se materializan y ejecutan mediante las modalidades e instrumentos de cooperación (Cuadro 1).

La Estrategia de Cooperación tiene dos especificidades que resultan relevantes de cara al objetivo de la investigación. En primer lugar, los criterios -principios- orientadores de la cooperación chilena son coincidentes con los principios de la css. En concreto, se trata de los principios de "apropiación, alineamiento con las prioridades nacionales y la transparencia", así como con un enfoque de responsabilidad mutua, articulación entre actores, liderazgo compartido y proceso participativo. Se pretende que "el conjunto de los actores implicados (cooperantes, intermediarios, receptores y/o beneficiarios) en los procesos de cooperación deben hacerse cargo de las acciones y consecuencias de los proyectos [...] lo que permite definir con las partes de modo más preciso el qué, cómo y cuánto" así como "asegurar que sus visiones [de la contraparte] sean tenidas en cuenta" (Agcid, 2015a, pp. 6-7).

\section{Ecosistemas multiactor y su funcionamiento}

La relación entre la Agcid y el resto de los actores no gubernamentales ha atravesado por un proceso de reconocimiento y fortalecimiento aún no institucionalizado. En la Estrategia de Cooperación 2015-2018 se reconoce que la cooperación "debe tender al trabajo conjunto con una multiplicidad de actores, reconociendo [especialmente] el rol de la sociedad civil y sus trayectorias, capacidades y conocimiento acumulado" (Agcid, 2015b). Pero la realidad

\footnotetext{
13 El gobierno chileno define el desarrollo desde una perspectiva multidimensional que trasciende la dimensión exclusiva de crecimiento económico como "un concepto que contempla y considera las características culturales de la sociedad en la cual se manifiesta; que busca y profundiza formas sociales equilibradas, en las cuales se establecen oportunidades similares para todos los miembros de la comunidad, posibilidades ciertas de avances en la base productiva, que construye y abre espacios para el bienes individual y colectivo" (Agcid, 2015).
} 


\section{Cuadro 1}

\section{Estrategia de cooperación internacional para el desarrollo de Chile, 2015-2018}

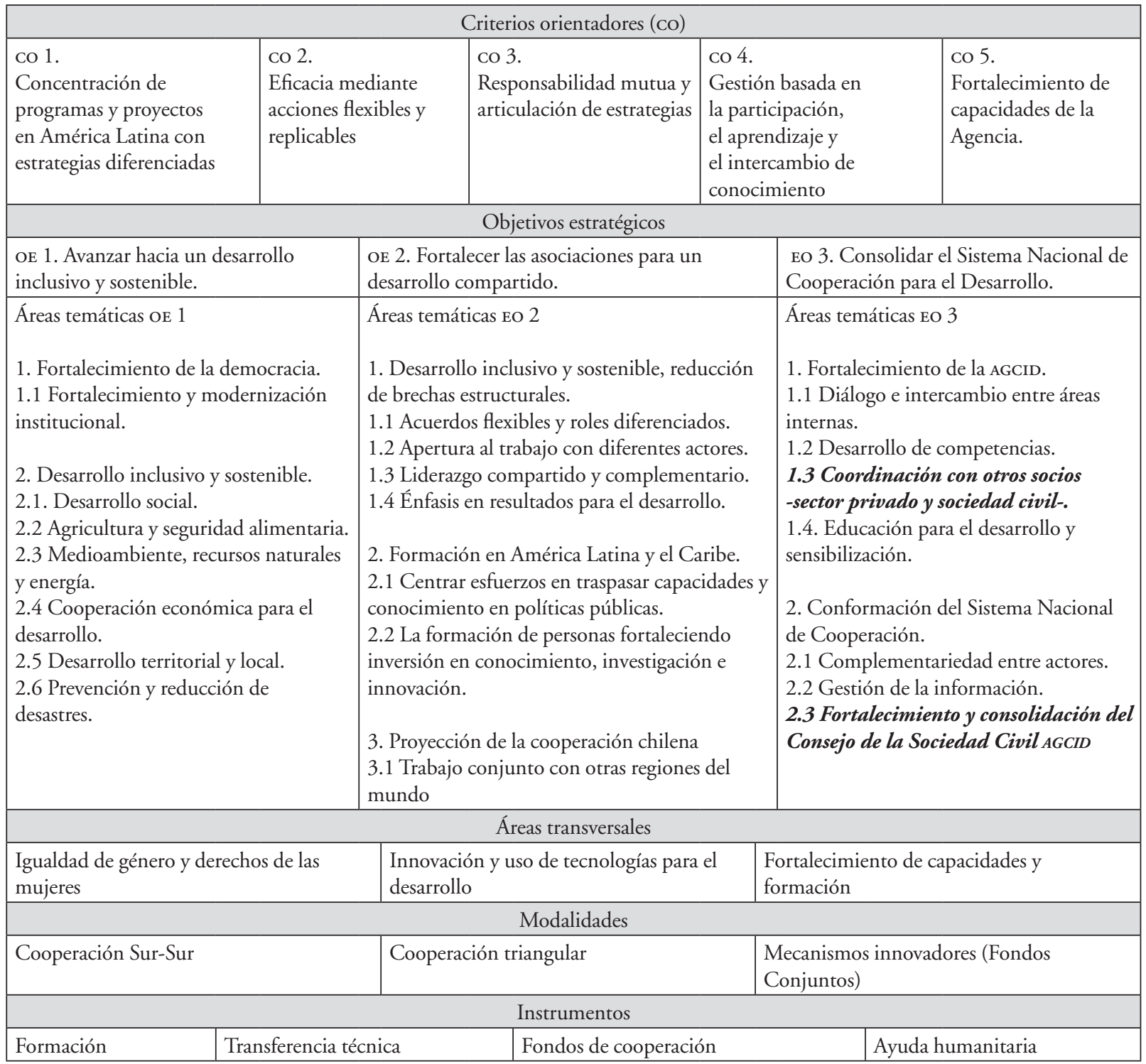

Fuente: Agcid, 2015b 
revela que estos actores aún no se encuentran representados en ningún mecanismo de diálogo o coordinación directa con la Agcid. Su participación hasta el momento es la propia de "socios técnicos", que aportan capacidades instaladas y conocimientos acumulados a la oferta de cooperación de Chile.

Por su parte, se han dado también pasos con el sector empresarial para avanzar hacia una relación de "socios técnicos", intentado vincular las áreas de responsabilidad social corporativa con proyectos e iniciativas de oferta de cooperación. Ya existen evidencias, por ejemplo, con la Confederación de la Producción y el Comercio (CPC), la Sociedad de Fomento Fabril (Sofofa), la Confederación Gremial Nacional Unida de los Servicios y Artesanado de Chile (Conupia), Centro de Investigación de Políticas Públicas para las Pymes (Cipyme), por mencionar algunas. Sin embargo, esto aún no se logra materializar y no hay iniciativas próximas que den aviso del establecimiento de mecanismos o procesos de diálogo más concretos entre la Agcid y el sector empresarial, siendo "una iniciativa que se encuentra sobre la mesa y que permitiría proyectar las capacidades nacionales más allá del ámbito de la administración pública"14.

\section{Desafíos}

Para su adecuada gestión y ejecución la cooperación internacional demanda una comunicación y articulación con diferentes actores tanto al interior como afuera de las instancias gubernamentales. En este sentido, uno de los primeros desafíos que se observan en el caso chileno para estructurar un ecosistema multiactor eficaz, es el que tiene que ver con la coordinación interinstitucional. Como en otros países, muchas de las entidades del Estado chileno gestionan y ejecutan cooperación para el desarrollo de manera independiente, quedándose fuera del "radar" de la actividad de coordinación que se hace desde la Agcid. Tales iniciativas de cooperación quedan fuera del registro de la entidad coordinadora, debilitando con ello la consolidación de un sistema de cooperación chileno y la plena visibilización de los esfuerzos que Chile hace como proveedor de cooperación.

Este hecho confirma la conveniencia de establecer mecanismos de diálogo y coordinación interinstitucional en los que las entidades de gobierno no solo den cuenta de su actividad sino sean actores activos en la definición de prioridades, formulación de iniciativas e identificación de capacidades que Chile puede ofertar como proveedor de cooperación, además de ser "brazos ejecutores" de la cooperación que oferta el país.

Un desafío adicional que se observa es en relación con la partición de actores no estatales en la cooperación chilena. Si bien la participación de actores no estatales forma parte de su mandato normativo, en la práctica aún es largo el camino para mejorar la comunicación y coordinación con los actores gubernamentales,

14 Funcionarios de la Agcid, entrevistas realizadas noviembre-diciembre, 2016. 
a fin de promover una oferta de cooperación inclusiva y participativa en la que se reconozcan las capacidades no gubernamentales con la que cuenta el país para su oferta de cooperación.

Se considera clave no solo identificar y mapear los actores a nivel nacional que ejecutan y emprenden acciones de cooperación, reconociendo qué cooperación hacen y con qué actores se relacionan, sino además sería oportuno resguardar el vínculo con estos actores a fin de que se conviertan en agentes de cambio, compartiendo sus conocimientos y experiencias, y sean parte de un proceso inclusivo para la definición de estrategias de la cooperación chilena.

Al respecto, es necesario que la Agcid fortalezca su estructura $-y$ se modifiquen su estatus y mandato- a fin de que tenga la atribución formal y capacidad para ser un agente coordinador del sistema nacional de cooperación, contando con una área específica encargada de coordinar la relación con los sectores nacionales, verifique su participación en la definición e implementación de los proyectos de cooperación y establezca mecanismos de acercamiento, diálogo y coordinación interinstitucional multinivel y multiactor en el que los diversos actores sociales puedan encontrarse representados.

\section{c. Colombia}

Colombia, al igual que los dos casos antes estudiados, transita en los últimos diez años desde un papel de receptor de cooperación hacia uno donde se hace presente su doble condición de proveedor y receptor. Los más de 37,7 millones de dólares que se han destinado a la css desde 2011 al 2016 son referencia del compromiso creciente de Colombia para posicionarse como oferente activo de cooperación. No obstante, Colombia ha puesto sus esfuerzos en visibilizar el "valor agregado" de la cooperación que oferta, más allá que los recursos financieros que esto pueda suponer. En este sentido, una de las principales características de la cooperación colombiana es su manera innovadora de guiar sus acciones de cooperación: a través de "alianzas estratégicas", en las que no solo se involucra a actores gubernamentales subnacionales (municipios y departamentos) sino también a actores no gubernamentales como las universidades, fundaciones y las organizaciones de la sociedad civil.

Al respecto, desde la propia Agencia Presidencial de Cooperación de Colombia (APC-Colombia) se reconoce que Colombia "no pretende tener un liderazgo en la región como oferente de cooperación neto ni como vocero en foros internacionales" 15 . El objetivo de la APC-Colombia más bien "es consolidar a la institución como una agencia especializada y referente en temas de intercambio de conocimiento de valor y aprendizaje para el desarrollo" (APC-Colombia, 2015), teniendo un rol como actor que contribuye al fortalecimiento de la css desde propuestas innovadoras enfocadas en metodologías y procesos como es el desarrollo de las "alianzas estratégicas".

15 Funcionarios de la APC-Colombia, entrevistas realizadas en octubre-noviembre, 2016. 


\section{Normativa}

En noviembre de 2011, el gobierno nacional, mediante el Decreto 4152, escinde algunas funciones de Acción Social y crea la APCColombia. A esta instancia se le encomienda la tarea de "coordinar el diseño, ejecución, seguimiento y evaluación de los programas y proyectos de Css y triangular" (Dafp, 2011, p. 8). A través del Decreto 4152 se define, con mayor claridad, la división de trabajo entre la Agencia y la Cancillería, así la primera es responsable de la coordinación y ejecución de la cooperación, es decir el "brazo técnico" de la política, mientras la segunda es la responsable de definir las prioridades y líneas de acción de la cooperación. No obstante, la APC-Colombia ha contado con un creciente protagonismo en la definición de prioridades y estrategias, sobre todo, de la oferta de cooperación colombiana. Por ejemplo, la relevancia de visibilizar el valor agregado de la cooperación, la identificación y sistematización de las experiencias nacionales que guían el establecimiento de relaciones de colaboración con los países socios, y la relación con actores no estatales vinculados a la práctica de la cooperación, son líneas de trabajo impulsadas básicamente por la APC-Colombia.

Si bien la cooperación colombiana no cuenta con una ley que sustente jurídicamente su quehacer, desde el 2004 se han diseñado tres estrategias nacionales de cooperación internacional (2004-2006; 2007-2010; y 2012-2014) con el propósito de definir las líneas de acción que deben orientar la cooperación internacional que recibe y oferta el país. En 2015 se elabora la "Hoja de Ruta de la Cooperación Internacional 2015-2018", documento apro- bado por el Consejo Directivo en mayo de 2015 y que se sustenta en el Plan Nacional de Desarrollo 2014-2018 "Todos por un Nuevo País: Paz, Equidad y Educación". Esta Hoja de Ruta tiene dos objetivos: a) Focalizar y dinamizar la cooperación que recibe el país; y, b) Compartir conocimiento de valor con países de desarrollo. Para cumplir este segundo objetivo, la APC- Colombia cuenta con cuatro mecanismos de acción: i) estrategias regionales; ii) programas bilaterales de cooperación; iii) alianzas estratégicas con diversos actores; $y$, iv) apoyo a los procesos de integración regional. En línea con el objeto de estudio que corresponde, las alianzas estratégicas son canales a través de los cuales la APC Colombia establece un acuerdo "gana-gana" con un socio público, privado, sociedad civil y/o academia con el fin de potenciar el intercambio de aprendizajes y la participación en la cooperación de diferentes actores.

\section{Ecosistema multiactor y su funcionamiento}

En 2015, la APC-Colombia puso en marcha una estrategia para desarrollar "alianzas estratégicas" a través de las cuales articular actores y aliados estratégicos para que los proyectos se conviertan en programas de mayor alcance e impacto. Se estimaba que las "alianzas estratégicas", eran "el canal por medio del cual se establece un acuerdo gana-gana con diversos actores a través de diferentes modalidades [...]. Estos acuerdos deben apalancar recursos, apuntar a un resultado claro y mutuamente beneficioso y agregar valor" (APC-Colombia, 2015 , p. 33). Se trata de sumar a organizaciones de la sociedad civil, fundaciones, sector 
privado, organismos internacionales y academia. La APC-Colombia busca con estas alianzas construir redes de colaboración para apoyar iniciativas innovadoras y sostenibles que contribuyan al posicionamiento de los actores involucrados mediante su participación en proyectos de cooperación, al desarrollo del país y respaldando el proceso de construcción de paz, y coadyuvar en el proceso de desarrollo de países socios. Se espera que las alianzas sean un rasgo característico de la cooperación colombiana constituyendo un "triángulo del éxito" interactuando el sector público, las empresas privadas y la sociedad civil para desarrollar proyectos duraderos y exitosos (APC-Colombia, 2015, p. 32).

El caso paradigmático de un ecosistema multiactor en Colombia, es el que se observa en la Mesa Distrital de Cooperación y Alianzas para el Desarrollo (Mecad). La Mecad es una alianza multiactor en la que participan entidades privadas, fundaciones del nivel nacional, departamental, municipal, universidades, gremios y ONG nacionales e internacionales lideradas por la Alcaldía de Cartagena de Indias. Un ejemplo de este esquema "ganar-ganar" que se espera de las alianzas estratégicas, es el beneficio que ha supuesto para esta todos los actores involucrados, en tanto que la participación de la Escuela Latinoamericana de Cooperación Internacional de Desarrollo ha posibilitado el fortalecimiento de la Mecad y sus miembros, pues gracias a los cursos de formación y especialización que brinda la Escuela a diversos funcionarios de la Alcaldía de Cartagena, así organizaciones de la sociedad civil local y empresas han fortalecido sus conocimientos y competencias para ejecutar, de manera más eficaz, la cooperación. La Mecad es ejemplo de que es posible organizar, coordinar y articular a un conjunto de actores que antes realizaban cooperación de manera dispersa - provocando, incluso, solapamientos de trabajo- de una manera eficaz y sostenible. $\mathrm{Al}$ respecto, miembros de la Mecad aseguran que "es un ejemplo de la relación beneficiosa que existe del trabajo conjunto y coordinado entre los actores" 16 .

Aunque la articulación entre APC-Colombia y las entidades ejecutoras de la cooperación "ha costado años de maduración institucional" (Uribe, 2011, p. 70), en los últimos años se observa una mayor comunicación y mejor trabajo coordinado entre el organismo encargado de dirigir y coordinar la cooperación internacional y las instituciones gubernamentales que, de manera dispersa, han desarrollado acciones y proyectos de oferta y recepción de cooperación, como lo muestra el caso de la Mecad y otros.

\section{Desafíos}

Si bien Colombia cuenta con uno de los casos paradigmáticos en torno a la creación y consolidación de un ecosistema multiactor eficaz a nivel local, aún parece necesario generar y

16 Rodríguez, Gustavo, Investigador de la Universidad del Norte, entrevista realizada octubre-noviembre, 2016; Funcionarios de la Alcaldía de Cartagena, entrevista realizada octubre-noviembre, 2016. 
fortalecer mecanismos de diálogo y coordinación entre actores a distintos niveles. Uno de estos escenarios es el que se produce entre APC-Colombia, Cancillería y el Congreso, en donde parece no existir un debate a nivel nacional sobre la política de cooperación, sus objetivos, alcances, relevancia y, sobre todo, la importancia de colocarla como una política de Estado. Pese al incremento de los recursos y el creciente fortalecimiento institucional, el debate entre los principales órganos de gobierno y coordinación de la cooperación colombiana sigue manteniendo un perfil de muy bajo nivel político en el país. De hecho, parece observarse cierta apatía y desinterés por parte de las entidades -APC-Colombia, Cancillería y el Congreso- para iniciar un diálogo sobre el papel de Colombia en el sicD. Un claro ejemplo de ello es la falta de una Comisión parlamentaria en la materia que dé seguimiento desde el Congreso a las acciones de cooperación que realiza el país, incluso no hay registro de que funcionarios de la APC-Colombia, como entidad vinculada a la Presidencia, hayan comparecido ante el Congreso como un mecanismo de rendición de cuentas.

Un reto más a superar tiene que ver con la relevancia por fortalecer la comunicación interinstitucional, es decir, entre el conjunto de las entidades gubernamentales a fin de identificar y focalizar la oferta y demanda de cooperación y construir una estrategia de cooperación programática a largo plazo. Y un tercer desafío es el que se relaciona con crear y consolidar un ecosistema multiactor en el que se articulen los órganos de gobierno y coordinación -APC-Colombia, Cancillería y Congreso-, el conjunto de entidades secto- riales gubernamentales y gobiernos subnacionales y los actores no gubernamentales con el propósito de hacer frente a una agenda de desarrollo global multinivel y multiactor como lo es la Agenda 2030 que demanda un trabajo articulado, transversal, horizontal y desde lo local con una perspectiva global.

Si bien estas alianzas se han construido desde la práctica más que desde la institucionalidad, se percibe oportuno tener en cuenta las lecciones aprendidas de la Mecad y avanzar en el desarrollo de espacios e instrumentos de comunicación, coordinación y articulación de trabajo entre actores a nivel nacional. Esto permitiría que la APC-Colombia, como entidad nacional encargada de gestionar y coordinar la cooperación del país, pueda cumplir con sus labores de manera más eficaz, facilitando que se asuma un rol activo -como ejecutor- y estratégico -como tomadores de decisiones- de todos los actores sociales, siendo parte en los procesos de definición, desarrollo, seguimiento, monitoreo de la cooperación colombiana, fortaleciendo con ello el sistema nacional de cooperación para el desarrollo.

Lo anterior se vuelve un imperativo, en un contexto interno de construcción de paz. Esta coyuntura demanda la creatividad, innovación y articulación de todos los actores sociales para adaptar los distintos instrumentos y modalidades de la cooperación a fin de que esta coadyuve de manera eficaz en la consolidación del proceso interno, pero también a la consecución de la paz regional e internacional como un bien público y uno de los ods de la Agenda 2030. 
4. CONTRASTANDO LA APROPIACIÓN NACIONAL: UNA DÉBIL INCLUSIÓN DE ACTORES NO ESTATALES EN LAS ACCIONES DE CSS

La apropiación nacional implica un proceso endógeno de formulación de políticas y fortalecimiento de capacidades técnicas e institucionales bajo el liderazgo de los países demandantes de cooperación. Este proceso motiva la búsqueda de soluciones locales a problemas de desarrollo locales. Por tanto, la apropiación nacional, como proceso endógeno, no solo motiva la generación de la demanda por parte del propio país solicitante, sino también alienta la participación de diversos actores nacionales gubernamentales y no gubernamentales en los procesos de definición y adaptación local de las iniciativas, evitando la mera asimilación de soluciones externas.

De las variables determinantes relacionadas con la apropiación nacional, la participación multiactor es la que presenta mayor debilidad. En una escala del 0 a 1 , esta variable puntúa un 0,35. Con mayor fuerza se muestran la capacidad efectiva de decisión del socio demandante $(0,83)$ y la demanda $(0,72)$, respectivamente.

Esta jerarquía se confirma cuando se consideran las respuestas de las personas representantes del socio demandante. Al respecto, el $92 \%$ de las personas señalan que tuvieron bastante o completa capacidad de decisión efectiva en todas las fases del proyecto: identificación y diseño (ID); negociación y aprobación (N\&A); gestión e implementación $(\mathrm{G})$; y finalización (Fin) (Gráfico 2).

\section{Gráfico 1 \\ Presencia de las variables \\ de la apropiación nacional}

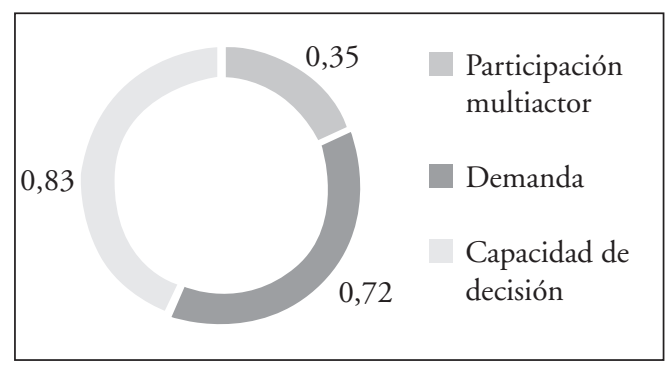

Fuente: Elaboración propia

El protagonismo del país demandante es menos nítido cuando se refiere a la solicitud del proyecto. Aunque el $41 \%$ de las personas consultadas apuntó que el proyecto de cooperación en el que participó fue solicitado de manera exclusiva por el socio demandante, un $56 \%$ señaló que la solicitud tuvo lugar en un marco común entre los socios bajo canales e instrumentos de diálogo y concertación conjunta (convenios de cooperación y/o comisiones mixtas). En este caso no es posible saber con certeza si la iniciativa es motivada y liderada por el socio receptor (Gráfico 3).

Finalmente, respecto a la participación de distintos actores sociales en las etapas del proyecto: identificación, formulación, implementación y evaluación, son los ministerios y entidades responsables de la coordinación gubernamental de la cooperación los que mayoritariamente participan durante todas las fases de los proyectos de cooperación. Los gobiernos locales y los centros de estudios están igualmente presentes, aunque con una cuota menor, siendo la sociedad civil y el sector 


\section{Gráfico 2}

\section{Capacidad de decisión efectiva del socio beneficiario en cada fase del proyecto}

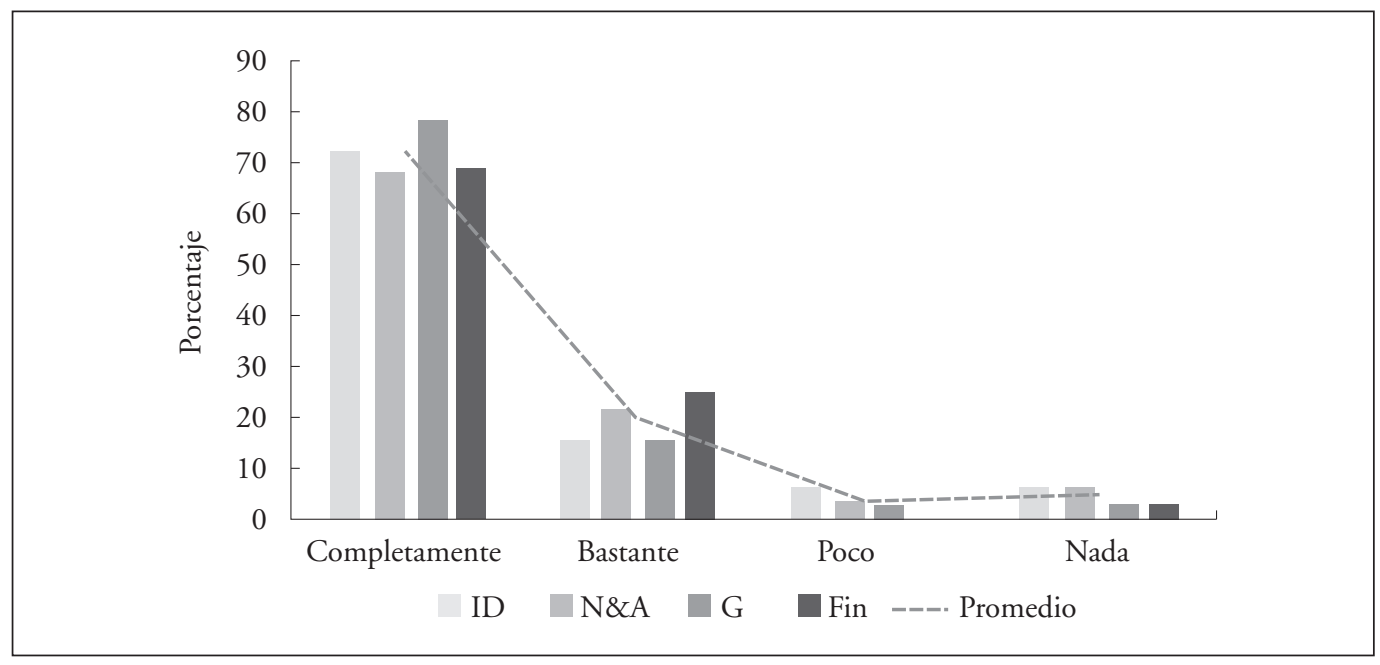

Fuente: Elaboración propia

Gráfico 3

Participación de las partes en la solicitud del proyecto

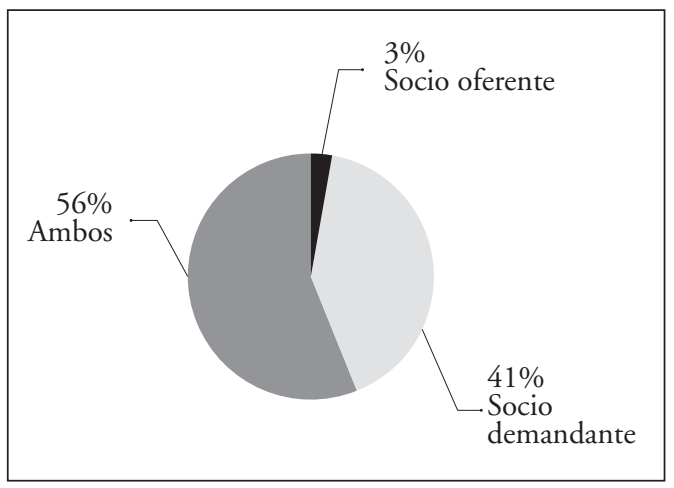

Fuente Elaboración propia privado los que aparecen con una más baja participación (Gráfico 4).

Estos resultados parecen ser coincidentes con estudios previos que ya advertían de la escasa participación de los actores no gubernamentales en los proyectos y acciones de css (Bobiash, 1992; Marín y Buchelli, 2010; Pino y Linaje, 2012; Balbis, 2013; Dolcetti, 2014; entre otros) y suponen un paso hacia delante en contar con un registro detallado sobre el grado de participación de los actores sociales en los proyectos de css, así como en conocer el rol y aportes de todos los actores no gubernamentales en la práctica de la css, más allá de centrar la atención exclusivamente en los actores públicos. 


\section{Gráfico 4}

Nivel de participación multiactor en las fases del proyecto

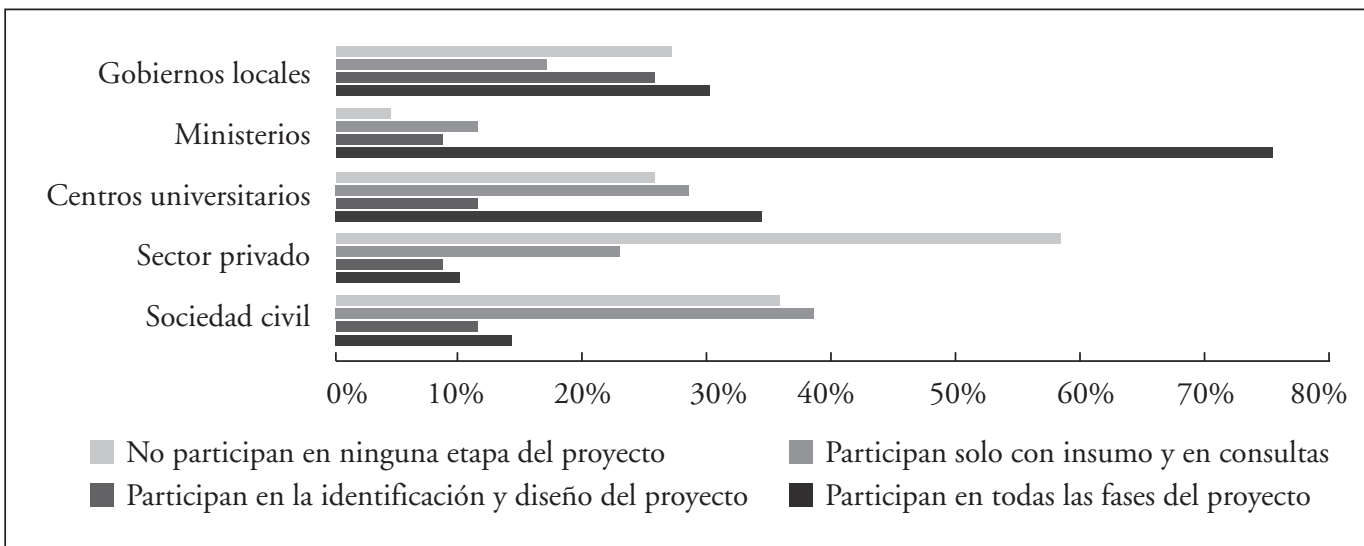

Fuente: Elaboración propia

\section{CONCLUSIONES}

Pese a que los marcos normativos y/o jurídicos sobre los que descansa la cooperación que ofertan México, Chile y Colombia adoptan los elementos discursivos de la css en lo relativo a la apropiación nacional y participación multiactor, aún no logran que estos se vean reflejados plenamente en sus procesos de gestión y práctica de su cooperación al desarrollo. Si bien se ha podido constatar que hay avances en la materia, en tanto que cada vez más los países cuentan con consejos de participación de actores no gubernamentales como mecanismos institucionales de articulación con los agentes gubernamentales, aún son escasos los espacios de participación y, los que existen, enfrentan desafíos en torno a su cobertura legal y geográfica, así como en las competencias y compromisos que adquieren los actores involucrados en la arquitectura nacional de la cooperación al desarrollo. Esto se traduce en la necesidad de continuar avanzando en impulsar las "alianzas estratégicas" y transitar del discurso hacia la creación de ecosistemas multiactor en donde se potencialice el rol de los diversos actores no gubernamentales y estatales en la coordinación, ejecución y evaluación de las intervenciones de cooperación.

Estos se perciben con claridad al momento de aterrizar el análisis a nivel proyecto, en donde la apropiación nacional muestra mayor debilidad en lo referente a la participación de diversos actores no gubernamentales en el diseño e implementación de las estrategias e iniciativas de la css. El estudio empírico que se realiza a partir de la muestra de proyectos de css aporta evidencia de la escasa participación de actores no gubernamentales en las distintas etapas del proyecto, lo que permite confirmar 
que aún se deben superar importantes desafíos para crear y fortalecer ecosistemas multiactor que involucren y articulen eficazmente a diversos actores sociales más allá del Estado, donde todos los actores sean agentes de cambio que compartan responsabilidades en la planeación, implementación y evaluación de las estrategias de cooperación, siendo un requisito "indispensable" de la css para lograr resultados efectivos y duraderos en materia de desarrollo (Ocde, 2011, p. 2).

Para concluir se considera conveniente mencionar dos líneas futuras de investigación que se derivan de este estudio. La primera se asocia con la posibilidad de indagar si las líneas de trabajo que promueven la creación y funcionamiento de ecosistemas multiactor incluyen procesos que permitan su evaluación respecto de su eficacia, es decir, conocer cómo impacta en los resultados de los proyectos. Y una segunda tiene que ver con conocer los recursos (humanos, técnicos y financieros) aportados por los actores no estatales participantes en los proyectos (Balbis, 2013). Contar con más ejercicios de sistematización y evaluación de proyectos de css permitiría identificar las potencialidades y áreas de mejora, para avanzar en la construcción de ecosistemas multiactor eficientes, en tanto que se logre la incorporación de diversos actores en las acciones de cooperación y, con ello, promover coherentemente el desarrollo sin dejar a nadie atrás.

\section{REFERENCIAS}

Agcid. (2015a): Politica Chilena de Cooperación Internacional para el Desarrollo 2030, en https:/www.
agci.cl/images/centro_documentacion/POLITICA_ DE_COOP_PARA_EL_DESARROLLO_26nov15.pdf Agcid. (2015b). Estrategia de Cooperación Internacional Chilena para el Desarrollo 2015-2018, en https:// www.agci.cl/images/centro_documentacion/EsTRATEGIA_DE_COOPERACI\%C3\%93N_26nov15. pdf

APC-Colombia. (2015). Informe de Gestión, diciembre. APCI. (2016). La cooperación internacional para el desarroIlo en América Latina en un contexto multiactoral. Documento de Trabajo, Redacción: Romero, F. (Cepei), Lima, Perú, p. 26.

Balbis, J. (2013). Las organizaciones de la sociedad civil y las asociaciones incluyentes para la Cooperación Sur-Sur en América Latina, Integration and Trade Journal, Banco Inter-americano, Intal, vol. 36(17), pp. 59-73.

Barros van Buren, M. (1990). Historia diplomática de Chile (1541-1958), 2a. ed., Santiago de Chile: Editorial Andrés Bello.

Bobiash, D. (1992). South-South Aid: How Developing Countries Help Each Other. London: St Martin's Press, pp. 224.

Bracho, G. y Pérez, J. (2015). Developmente Agenciesin Emerging Powers: The Mexican Case, en Sidiropoulos E., Pérez J. y Chaturvedi S. (Eds.) Institutional Architecture and Development. Responses from Emerging Powers, Sudáfrica: Saiia, pp. 168-186.

BRICs Policy Center; Articulação Sul. (2017). Paths for Developing South-South Cooperation Monitoring and Evaluation Systems, 1a. ed., Brasilia: Ministry of Foreign Affairs.

Bry, S. (2017). The Evolution of South-South Development Cooperation: Guiding Principles and Approaches, European Journal of Development Research, vol. 29, pp. 160-175. 
Calvento y Rolandi. (2015). Reconfiguración de la cooperación Sur-Sur en la región latinoamericana y la participación internacional de los actores subnacionales, Revista Mexicana de Ciencias Politicas y Sociales, año LX, No. 224, mayo-agosto Universidad Nacional Autónoma de México, pp. 315-348.

Cordeiro. (2012). De receptor a doador: os desafios da cooperação para o desenvolvimento na política externa brasileira sob a ótica da relação estado/ sociedade civil. Monçôes: Revista de Relaçốes Internacionais da UFGD 1(2), pp.140-163.

Dafp. (2011). Decreto 4152 que crea la Agencia Presidencial de Cooperación Internacional de Colombia, noviembre. En línea http://repository.icesi. edu.co/biblioteca_digital/handle/10906/67897

DESA/RIs. (2013). Conference of Southern Providers SouthSouth Cooperation: Issues and Emerging Challenges, 15-16 de abril, Nueva Delhi, en http://ris.org.in/ pdf/ssc_report_web.pdf

Dubois, A. (2001). Participación y desarrollo. En Grau P. e Ibarra E. (coords.), Participando en la red: anuario de movimientos sociales, Barcelona: Icaria Editorial, pp. 104-127.

Dubois, A. (2000). Definición Cooperación Internacional para el Desarrollo, en Pérez de Armińo, K. y Eizagirre, M. (Eds.), Diccionario de acción humanitaria y cooperación al desarrollo. Bilbao, España: Icaria Editorial Hegoa-Facultad de Ciencias Económicas-Universidad del País Vasco, España. En http://www.dicc.hegoa.ehu.es/listar/mostrar/41

Dolcetti-Marcolini, M. (2014). La participación de las organizaciones de la sociedad civil en la Cooperación Sur-Sur de Brasil: Buscando un enfoque integral de participación, en Iberoamerican Journal of Development Studies, 3 (2), pp. 130-147.

Herrera, O. (2009). Diagnóstico institucional y propuesta de mejoramiento de la Agci, en Estudios de Caso, No. 106, mgpp. En http://www.mgpp. cl/wp-content/uploads/2017/04/CAso106.pdf

Huitrón, A. (2018). Identidad de la cooperación Sur-Sury su contribución al sistema internacional de cooperación para el desarrollo. Las experiencias de México, Chile y Colombia, Tesis Doctoral, Madrid: UCM.

Huitrón, A. y G. Santander. (2018). Agenda 2030 de Desarrollo Sostenible y las implicaciones para América Latina y el Caribe, Revista Internacional de Cooperación y Desarrollo, vol. 5, (1), pp. 3-11.

Krupatini, S. (2011). ¿Y ahora qué hacemos ante la complejidad?, Buenos Aires-México-SantiagoMontevideo: Ediciones Granica.

Le Blanc. (2015). Towards integration at last? The sustainable development goals as a network of targets, Desa Working Paper, No. 141, marzo.

López, R. (2014). La cooperación Sur-Sur como instrumento de política exterior durante el periodo de la concertación, 1990-2010: El caso centroamericano, Instituto de Estudios Internacionales de la Universidad de Chile.

Marín, M. y F. Buchelli, (2010). Sociedad civil y países emergentes, los protagonistas, en Revista de la Universidad Externado. Enlace: https://www. researchgate.net/profile/Fernando_Bucheli/publication/280623898_Sociedad_civil_y_paises_emergentes_los_protagonistas_Social_Civil_Organisation_and_Emergent_Countries_ key_actors/links/55bf806908ae9289a09b5889/ Sociedad-civil-y-paises-emergentes-los-protagonistas-Social-Civil-Organisation-and-EmergentCountries-key-actors.pdf

Naciones Unidas. (2009). Documento final de Nairobi de la Conferencia de Alto Nivel de las Naciones Unidas sobre la Cooperación Sur-Sur, Resolución A/REs/64/222/ En http://www.un.org/es/comun/ docs/?symbol=A/REs/64/222 
Ocde. (2011). Hacia una Cooperación Sur-Sur y Triangular Efectiva, Documento de Buenas Prácticas. Octubre.

Pino E. y C. Linaje. (2012). Concentración sectorial en la cooperación española: claves para una mayor apropiación democrática. España: Coordinadora de ONG para el Desarrollo y Agencia Espańola de Cooperación. En https://coordinadoraongd.org/ old/1026/original/ConcentracionSectorialcE.pdf

Prado, J.P. (2013). México. La cooperación Sur-Sur y triangular. El dinamismo vuelto desafío, en Ayllón B. y Ojeda T. (Eds.), La Cooperación Sur-Sur y triangular en América Latina. Politicas afirmativas y prácticas transformadoras, IUDC-UCM, Madrid, pp. 180-200.

Saiia. (2017). A Monitoring And Evaluation Framework For South-South Cooperation, Autores: Neissan Besharati, Carmel Rawhani and Ornela Garelli Riosen. En línea http://www.saiia.org.za/ research-reports/a-monitoring-and-evaluationframework-for-south-south-cooperation
Santander, G. (2016). Identidades e intereses de la cooperación Sur-Sur. Los casos de Chile, Venezuela y Brasil, Madrid: Los Libros de la Catarata.

Segib. (2018). Una década de cooperación Sur-Sur en Iberoamérica, Madrid: Segib y Turner.

Segib. (2010). Informe de la Cooperación Sur-Sur, Madrid, España.

Tripp J.O. y Vega B. (2011). Asociaciones complementarias: Base para el futuro de la Cooperación Sur-Sur y triangular de México, Revista Española de Desarrollo y Cooperación, No. 28, Madrid: IUDC-UCM, primavera-verano, pp. 29-42.

Uribe, P. (2011). Colombia: Hitos y tendencias como nuevo donante, en Santander (Coord.), Nuevos donantes y Cooperación Sur-Sur: estudios de caso, Madrid: ICEI-UCM, pp. 63-87.

Walker, I. (2006). La política exterior chilena, en Revista Estudios Internacionales, vol. 39, No. 155. pp. 9-35. 